\title{
Comparing Asynchronous and Synchronous Video vs. Text Based Discussions in an Online Teacher Education Course
}

\author{
Cynthia Clark and Neal Strudler and Karen Grove \\ University of Nevada, Las Vegas
}

\begin{abstract}
The purpose of this study was to investigate whether asynchronous video posts and synchronous videoconferencing would create higher levels of teaching and social presence within an online course when compared with the university's current text-based discussion platform. Undergraduate students in an online teacher education course were randomly assigned to either the text-based discussion platform or the video-based discussion platform. A switched replications design was used and halfway through the semester students switched platforms. Analysis of student interviews and surveys administered at the end of the semester indicated self-reported perceptions of social and teaching presence were significantly higher when using the video-enabled discussion site. Implications of the added value of video, both in synchronous and asynchronous contexts, are discussed and recommendations for further study are provided.
\end{abstract}

\section{Introduction}

Today online learning, learning that occurs at a distance where the learner uses some type of technology to interact with the instructor and other learners (Anderson, 2004), is no longer relegated to non-traditional students. Enrollment levels at predominantly online schools such as the University of Phoenix, Kaplan University, and Western Governors University are influencing traditional institutions to increase their number of online offerings (Burnsed, 2011). Massively open online courses, or MOOCs, are adding to the pressure to increase the number of online courses as states such as California seek to reduce the cost and time required by students to obtain post-secondary degrees, thereby expecting to help increase graduation rates (Fain, 2013). 
Unfortunately, online instruction has not appeared to increase graduation rates. Attrition is significantly higher for online students than for students attending traditional classrooms (Doherty, 2006; Patterson \& McFadden, 2009). Time constraints as well as work and family obligations were cited as posing limitations on the amount of time online students could devote to their coursework. Online students' feelings of isolation have been identified as one factor that can lead to attrition (Rovai, 2003). Students stated that that they felt alone and they missed attending class with other students (Dickey, 2004). The odds of students persisting in a course were positively related to their feelings of social presence (Liu, Gomez, \& Yen, 2009), “the ability of participants...to project their personal characteristics into the community, thereby presenting themselves to the other participants as real people" (Garrison, Anderson, \& Archer, 2000, p. 89). Students were more likely to stay in the course as feelings of social presence increased.

It is important that online instructors employ methods that will help reduce students' feelings of isolation. The purpose of this study was to determine whether the integration of asynchronous video posts and synchronous videoconferencing as part of a discussion platform would more effectively help increase feelings of social and teaching presence when compared with the currently used text-based discussion tool. As the course platform employed, WebCT, did not allow students to easily incorporate video posts in the text-based discussion format, it was decided that Google+ would be used to host class discussions. Google+ launched in June 2011 (Kaste, 2011) as a free social networking site and can be accessed by any online instructor and student. Google+ incorporates videoconferencing, referred to as 'Hangout', and has the ability to create video posts directly within the platform. By comparing student discussion experiences with text-based versus video-based platforms, this study sought to answer the following research questions:

1) What differences in social presence, if any, did students perceive between communications with video versus text-based communications?

2) What differences in teaching presence, if any, did students perceive between communications with video versus text-based communications?

\section{Theoretical Perspectives}

The theoretical framework for social and teaching presence guiding this study was drawn from the Community of Inquiry (CoI) model developed by Garrison, Anderson, and Archer (2000). The basic elements of the model are Social Presence, Teaching Presence, and Cognitive Presence. Social presence is "the ability of participants in the Community of Inquiry to project their personal characteristics into the community, thereby presenting themselves to the other participants as real people" (Garrison et al., 2000; p. 89). Teaching presence consists of three areas: instructional design, facilitation of discussion and direct instruction, along with displays of personality that demonstrate humanity (Nowak, 2001). Cognitive presence is "...the extent to which the participants of a community of inquiry are able to construct meaning through sustained communication” (Garrison et al., 2000; p. 89). Teaching and social presence support cognitive presence by creating the environment necessary to sustain the communication required to construct meaning.

The early descriptions of the CoI framework imply set characteristics and relationships. More recent investigations have hinted that a dynamic relationship exists and that there can be an ebb and flow of the presences as a course progresses (Akyol, 2014). This may be due to the group nature of social presence. It is not only individual presence that is important in the development of a CoI, there must be group cohesion as well (Remesal \& Colomina, 2013). Student on-task behavior will vary based on their interest on various tasks, thus increasing and decreasing their participation in the group. 
Discussion boards are the primary form of communication between students and instructors for online courses, which make them the focus for the creation of social and teaching presence in those courses. While social sharing has been shown to provide a pathway to social presence (Kreijns, Kirschner, Jochems, and Van Burren, 2004), the sharing must have a purpose and be linked to group identity (Remesal \& Colomina, 2013). Feelings of group affiliation and group cohesion rather than perceptions of 'self' help build and sustain online learning communities where effective collaborations can occur (Pinsk, Curran, Poirier, \& Coulson, 2014).

\section{Online Discussion Boards and Presence}

Text-based discussion platforms have been shown to lead to teaching and social presence (Gunawardena \& Zittle, 1997; Nagel \& Kotze, 2010; Nowak, 2001) though this can be time consuming and complex due to the lack of non-verbal social clues (Rovai, 2001). Miscommunication can occur as actions might go unobserved for a period of time, and online discussions require a longer time frame to complete (Wang \& Woo, 2007). Due to inherent facial and physical clues in face-to-face discussions, they are perceived to be more authentic when compared with online discussions. Video discussions can help address this issue. Video posts provide necessary visuals, allowing students to experience each other as actual humans rather than text on a screen, thereby increasing social presence. This form of presence, aided by video, is "a psychological state in which virtual objects are experienced as actual objects in either sensory or nonsensory ways” (Lee 2004, p. 27).

Student performance has been shown to improve slightly when students are given the opportunity to participate synchronously through videoconferencing as compared with students who used only textbased learning materials (Skylar, 2009). Higher learning outcomes have also been shown to occur when students are provided with a combination of asynchronous and synchronous forms of communication ( Moallen, Pastore, \& Martin, 2011). Synchronous videoconferencing provided immediate social interaction and co-construction of knowledge while asynchronous text communication allowed for reflective thinking. Online video discussions develop group cohesion and affiliation, helping students to feel 'part of the group', thereby increasing engagement and participation (Pinsk et al., 2014).

In order to help create social presence within the computer supported collaborative learning (CSCL) environment, the environment must lend itself to the creation of a social space (Kreijns et al., 2004). Social space refers to the social interactions that occur among group members, the established group culture wherein beliefs and rules are developed, and the group ideals (Remesal \& Colomina, 2013). The extent to which social space is created within a CSCL is dependent upon the sociability of the environment. Sociability defines the characteristics of the environment that lead to the development of a social space and includes "strong group cohesiveness, trust, respect and belonging, satisfaction, and a strong sense of community” (Kreijns et al., 2004, p. 157). Sociability provides the structure needed to help develop social presence, while social space provides evidence that social presence has developed.

Teaching presence has also been shown to increase through the use of video posts. Voice Thread, a web-based application that allows users to create asynchronous video posts, was used as the communication tool for teacher preparation courses conducted at a large institution (Borup, West, \& Graham, 2012). Students indicated that watching instructors' video posts helped them see their instructors as real people, leading to feelings they were talking to their professors even though the video was asynchronous. Teaching presence is distributed among group members and is not strictly the purview of the instructor (Akyol, 2014). In the case of college courses, students primarily assist in the development of teaching presence by helping to facilitate course dialogue.

Video versus a text-based discussion platform is not the only factor that should be considered when designing a course discussion board. Group size can also have an effect on communication (Gall, 
1980). The most efficient group size for promoting task-oriented interactions during synchronous discussions is between two and three members (Tu \& McIsaac, 2002) as the smaller size allows members to participate equally. The discussion quality for computer mediated communication was found to be highest when group size was between three and six members (Lowry, Roberts, Romano, Cheney, \& Hightower, 2006). One reason for the discrepancy may be that synchronous discussions conducted by smaller groups experience less off-task behavior that results in greater knowledge construction (Schellens \& Valcke, 2004). Another reason for the difference in effective group size between synchronous and asynchronous discussions is that larger group sizes may increase the time needed to develop communication channels between individuals. This lag time may place obstacles to the formation of trust required for open discussions in a synchronous communication structure. Assigning students to subgroups within the overall course discussion platform can help students form relationships more quickly, resulting in increased "quality of discussion, communication appropriateness, communication richness, openness, and accuracy" (p. 656).

Teaching and social presence have been shown to improve student retention by helping to lessen feelings of isolation that can come with enrollment in online courses (Liu et al., 2009). Student responses pertaining to a university web-based teacher education course demonstrated feelings of loneliness and isolation. Student comments included “...missing being in a class with other students" as well as "I liked the convenience of the class but I felt like I was alone” (Dickey, 2004, p. 281). Such feelings of isolation can result in a lack of persistence for online students (Rovai \& Wighting, 2005). However, as student feelings of social presence increase, feelings of isolation decrease while student persistence tendencies increase (Liu et al., 2009). Teaching presence plays an important part at reducing isolation as well. The teacher acts as a facilitator in developing the learning community for his or her class (Doherty, 2006; Joo, Kim, \& Kim, 2011) by modeling communication and facilitation expectations (Akyol, 2014).

While these authors acknowledged that factors leading to attrition are complex, they all pointed to the lack of social and academic integration as primary factors. Academic integration, student satisfaction in intellectual development, is less dependent on the form of communication when compared with social integration. Social integration typically measures the satisfaction a student feels with the social aspects of life on campus (Munro, 1981). In relation to the online environment, social integration is related to feelings of social connectedness and group cohesion (Zydney, deNoyelles, \& Seo, 2012). Social presence provides an environment for this connectedness and group cohesion to develop. In turn, teaching presence has been found to be significantly correlated with student persistence due to its effect on social presence (Joo, Y-J, Lim, K-Y, Kim, E-K, 2011). Online instructors therefore need to help students cultivate social presence, enabling the development of a community of inquiry (CoI). The CoI helps facilitate the learning process and leads to increased student persistence (Garrison, Anderson, \& Archer, 2000; Tinto, 1997). In the present study we investigated whether students experienced a difference in teaching and social presence based on the discussion platform used during the online course.

\section{Method}

A mixed-methods action research approach was used to evaluate whether undergraduate teaching students perceived differences in teaching and social presence when using a platform that provided the ability to participate in synchronous videoconferencing and asynchronous video discussions (videoenhanced) (VED) as compared to the university's text-based discussion (TBD) platform. For the purposes of this paper, the acronym VED will refer to the video-enhanced platform and TBD will refer to the university's text-based discussion platform.

Mixed methods allows for a triangulation of data, helping to explain the data more fully by providing insight into complex human behavior (Cohen, Manion, \& Morrison, 2011). This study used 
non-parametric statistics to quantify the differences, if any, between the development of social and teaching presences based on student perception measured using survey instruments of the two discussion platforms. Interviews were conducted with some of the students in order to obtain a better understanding of student experiences using both discussion platforms and to help identify reasons for any differences that might be identified between the two platforms.

\section{Participants}

Undergraduate preservice teachers enrolled in an online teacher technology course at a large, urban university in a southwestern state were recruited to participate in this study. The course introduced students to educational uses of technology and was a requirement for graduation. Five of the 26 students elected not to participate in the study and an additional five students did not complete the course. This resulted in a participant sample of 16 students.

\section{Measuring Presence}

Sociability Scale, Social Presence Scale, and Social Space Scale. One of the goals of this study was to measure whether students perceived differences in the development of social presence based on the discussion platform used. As discussed above, sociability helps in the development of social presence, and social space provides evidence that social presence has occurred within the group structure. Therefore an instrument that measures all three constructs was chosen for this study. A modified combined version of Kreijns, Kirschner, Jochems, and Burren’s (2004) Sociability Scale, Social Presence Scale, and Social Space Scale was used to measure social presence. The theoretical framework for these scales includes an ecological approach, where the social affordances of the media are viewed as “...properties of a computer-supported collaborative learning (CSCL) environment that act as social-contextual facilitators relevant for the learners’ social interactions” (Kreijns, Kirschner, \& Jochems, 2002, p. 13).

Kreijns et al. used face-validity to develop items during a computer mediated communication (CMC) social interaction literature review. Cronbach's alpha measures reported in this article for the Sociability Scale, the Social Presence Scale, and the Social Space Scale respectively were 0.92, 0.81, and 0.91. Principal factor analysis with varimax rotation was used to confirm the uniqueness of each scale. In this study, two surveys were created and the questions contained in the three scales were adapted for use with the present online course. Most of the adaptation involved changing terminology for Google+. For example, "Google+ allows spontaneous informal conversations" and "Google+ enables me to identify myself with my group."

Teaching Presence Scale. The instrument used to measure teaching presence was the Teaching Presence Scale first developed by Rovai (2002) as part of the Classroom Community Index. Shea, Li, and Pickett (2006) used the instrument to investigate perceived differences in community when comparing face-to-face classes and online courses with respect to teaching presence. A principal component analysis was performed by Shea et al., (2006) to verify that the construct measured was teaching presence and the correlation coefficient for each item was greater than 0.30 . A reliability analysis indicated there was internal consistency of the learning community measure and the teaching presence scales. Cronbach's alpha values were calculated for the learning community scale, connectedness, and learning subscales and found to be 0.93, 0.91, and 0.90 respectively. In this study, the Teaching Presence questions were added at the end of the Social Presence survey items for each platform and included items such as "Overall, the instructor for this course helped to keep students engaged and participating in productive dialog."

These instruments were chosen as the basis for this study as they focus primarily on social presence and teaching presence. As stated earlier, cognitive presence was not explored in this study. Therefore it was decided that a more recent instrument developed by Arbaugh et al, (2008), would not be 
used. Many of the items on that instrument incorporated cognitive presence, and authors of that paper noted that some of the survey items were more highly correlated with cognitive presence than with teaching presence.

\section{Student Interviews}

A standardized open-ended interview method was used to obtain a more in-depth analysis of student perceptions of social and teaching presences associated with the two platforms. This technique used structured questions where each participant was asked the same question, but allowed response flexibility due to the open-ended nature of the questions (Gall, Gall, \& Borg, 2003). The interview contained questions about perceived differences between the use of VED and TBD in relation to the course and the instructor experience. The average interview length was 15 minutes.

\section{Procedure}

During the Fall 2012 semester one of the authors of this paper conducted a pilot study to determine whether the VED could effectively be implemented as a discussion board in an undergraduate online teacher technology course. As the purpose of the pilot study was to identify possible barriers to implementation and communication, data on social and teaching presence were not collected. That experience, as well as an extensive literature review, informed the procedures used for this study.

A preliminary technology survey was administered the first week of the Spring 2013 semester to determine student technology comfort level and gauge their experience with Web 2.0 applications. The results of the survey indicated that most students had high self-efficacy in their ability to learn and apply technology skills. It also indicated that all participants had access to the hardware necessary to successfully participate in video posts and videoconferencing.

Platform Assignment. At the beginning of the semester students were randomly assigned to treatments groups requiring discussions posts on either the text-based platform (TBD) or the videoenhanced platform (VED). Half of the students started the semester using the TBD and the other half of the students started the semester using the VED. There were concerns by the researchers the order of the platforms could affect student responses on the surveys. Beginning the semester with the VED may have caused students to develop feelings of social and teaching presence that extended into their use of the TBD, thereby inflating the scores for the TBD. Ending the semester with the VED may have caused inflation of scores on the VED survey as students would currently be using that platform during the administration of the survey. Therefore, a switched replications design was used to help balance out those possible effects.

A random number generator was used to determine group membership. All students participated in the experimental treatment; however data for those who declined to participate were not used for the study. On the eighth week students switched platforms, and for the final week all students used the VED platform. This resulted in students using each platform for seven weeks prior to the administration of the surveys, which occurred near the end of week 14 of the semester.

The students were further divided into smaller groups. The ideal group size for discussions has been shown to be dependent upon the type of communication. For synchronous communications, group sizes of two to three are considered to be most effective, while group sizes of three to six are considered to be most effective for asynchronous discussions (Lowry, Roberts, Romano, Cheney, \& Hightower, 2006; Tu \& McIsaac, 2002). For this study discussion group size was set at four as both types of communication were expected to occur. After having been assigned a platform, students were further divided into discussion groups at the beginning of the semester and remained in these groups throughout 
the term. The researchers believed this would allow group members to establish the level of trust and comfort necessary to collaborate effectively (Dooner, Mandzuk, \& Clifton, 2008). The created groups contained both females and males when possible and were based on the secondary subject area students planned to teach. Geographical locations of students' residences were also a consideration should students decide to meet face-to-face for collaborative purposes.

Creating the VED Course Page and TBD Discussion Format. Privacy is an important consideration when using an online social networking site (Buchanan, Paine, Joinson, \& Reips, 2006). Social networking sites such as Facebook, Twitter, and Google+ were originally created with the premise that ideas were to be shared around the world uncensored (Rosenblum, 2007). Privacy settings may not be as rigorous as some students may prefer, inhibiting participation. Therefore it was decided that the VED course page should be created to provide an extra layer of security. A Gmail account, a free web-based email service developed by Google, was created using the course name. Students, after establishing a Google account, were provided the link to the Google course page.

Circles are the method Google+ uses to group people who have been granted permission to read the user's postings. Circles provided control over who saw which particular posting and determined the level of privacy of each post. This was an important consideration as students must feel they are in a safe space in order for social presence to occur (Kreijns, Kirschner, \& Jochems, 2003). Three Circles were created which included all course members-a "Help" Circle, "Social" Circle for unrelated course content, and a "Communique" Circle which was used to share educational technology information the instructor encountered on the Internet.

Module Circles were created for the weekly course discussion assignments. The VED did not allow for threaded discussions, therefore Circles were created for all groups each week, allowing separation of the weekly discussion posts. Each week students accessed the course material through WebCampus, the university's designation for WebCT. Students were required to comment on the materials assigned each week and to include at least one quote that caught their interest as well as discuss how the topic may or may not contribute to student learning in their future classrooms. Providing a topic for discussions has been shown to encourage motivation to participate (Aviv, Erlich, Ravid, \& Geva, 2003; Garrison, Anderson, \& Archer, 2001). A “typical” video discussion post can be seen in Figure 1 below.

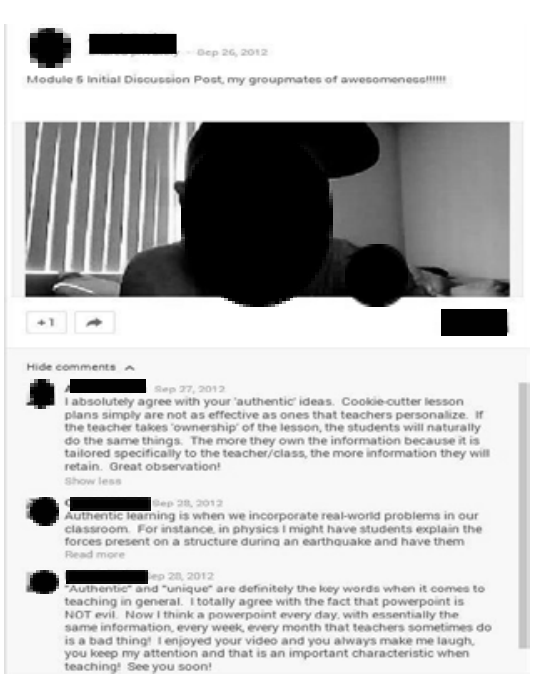

Figure 1. Initial student video post with accompanying follow-up text posts. 
A discussion rubric was used to grade each week's participation. Incorporating course discussions into the grade structure has been demonstrated to increase student motivation to participate (Kay, 2006). The rubric was based on the discussion structure necessary to generate reflection and social interaction that can lead to improved learning outcomes (Greenlaw \& DeLoach, 2003; Roblyer \& Wiencke, 2003). To help ensure the privacy of the posts, students were warned that public posts would receive zero points. Public posts can be accessed by anyone with a Google+ account, regardless of the fact that the post was created on a private Google+ page. Full participation consisted of one initial video/text post and three follow-up posts for each discussion and represented $22.5 \%$ of the course grade.

The TBD discussion board had a similar design. Threads were created which mirrored the three all-member Circles on the VED. Topics were created for each week's discussion. Threads within each discussion topic were created for each of the smaller discussion groups. Students assigned to the TBD group were instructed to post only to their assigned subgroup for each week's discussion. The title of the subgroup threads included student names to help clarify group membership. The TBD discussion board structure and thread structure can be seen in Figures 2 and 3 below.

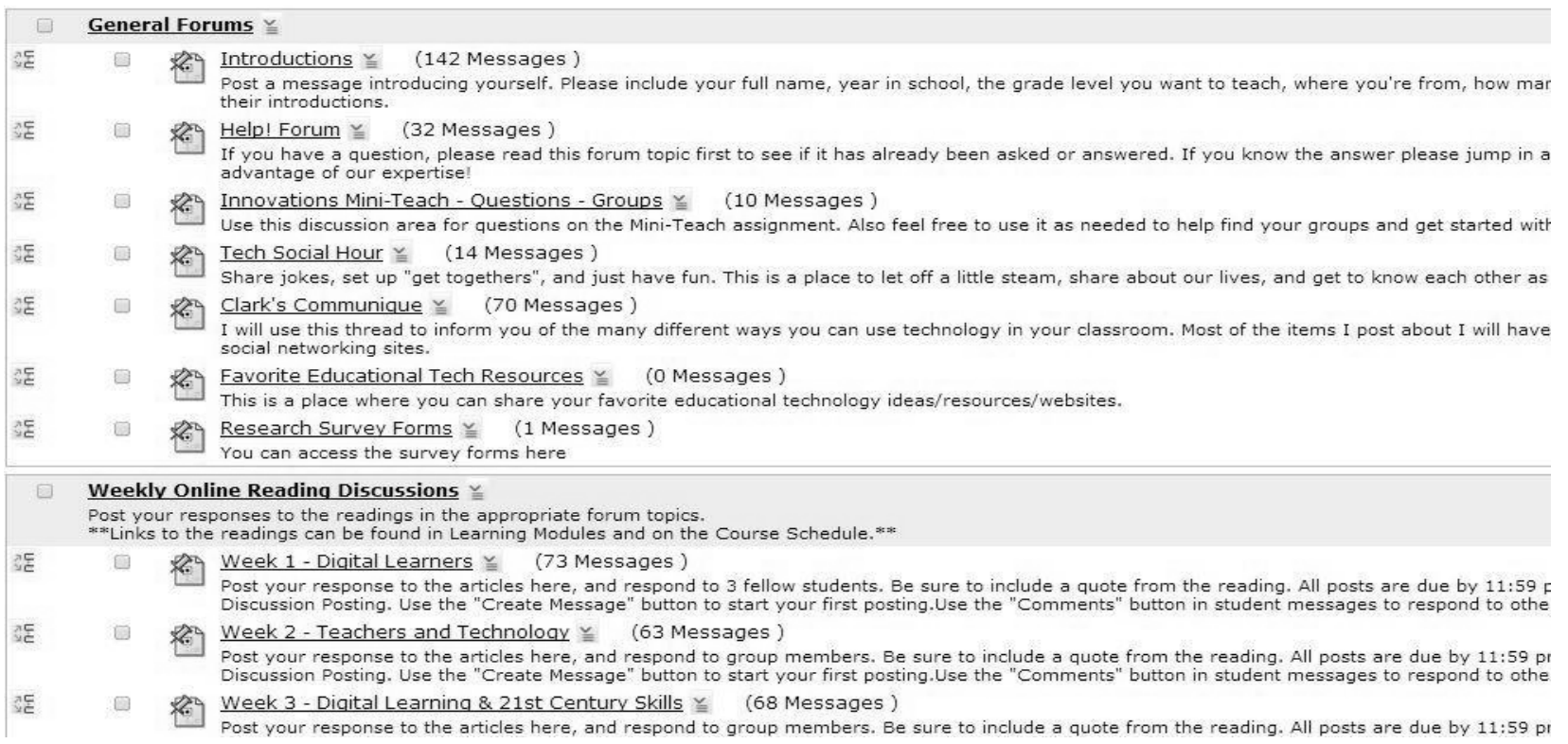

Figure 2. The structure and menu for the text-based discussion board

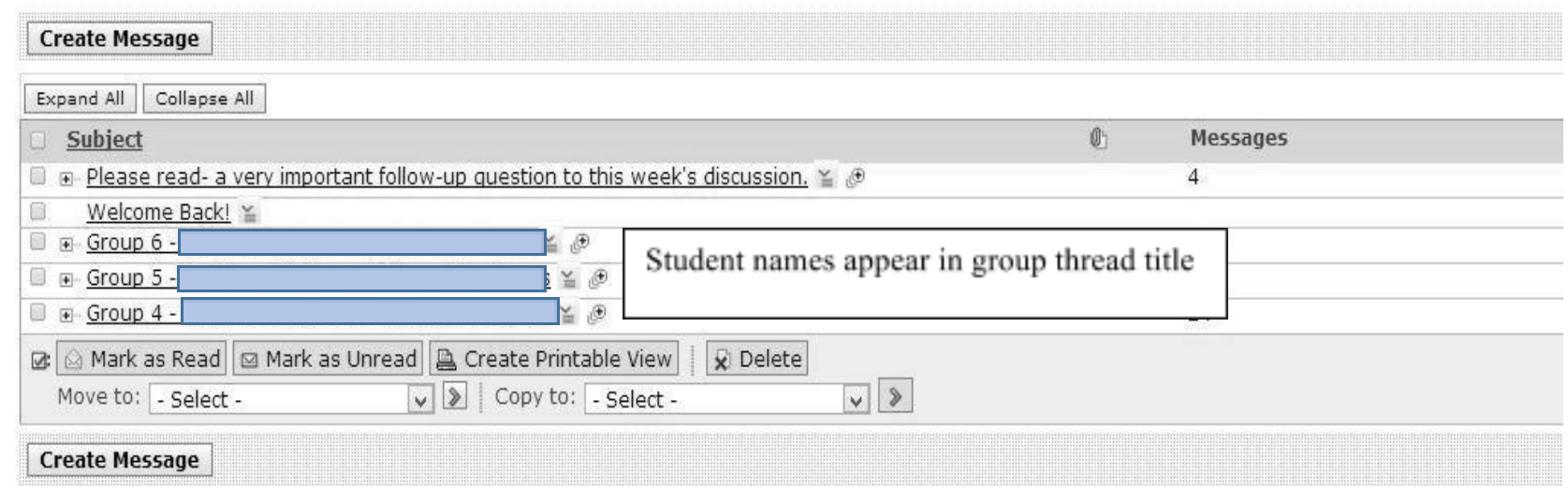

Figure 3. Demonstration of how groups were created for the text-based discussion platform. 
Teacher-Student Interactions and Teaching Presence. Screencasts were created by the instructor for each step required to communicate within the VED: creating the account, creating a video post, creating and sharing Circles, accepting a Circle, joining a Hangout, and starting a Hangout. Video posts were modeled by the course instructor. Figure 5 shows an opening scene from an instructor created video post. At the beginning of each week the instructor created a video post discussing the upcoming week's content and expectations. The video posts also included off topic conversations on happenings in the community or issues preservice teachers might find interesting. Similar content was provided on the TBD to ensure equal participation by the instructor on the two platforms. The week's text-based introduction post on the TBD platform was included in a separate thread under each week's discussion heading. The goal of these activities were help facilitate discussion, one of the primary components of teaching presence (Garrison et al., 2000).

Initiation to the VED. Students were notified at the beginning of the spring 2013 semester of their group and platform assignments. All students were required to access the VED tutorial materials and to complete the VED quiz during the first week. The VED quiz was designed to ensure students were comfortable with the VED's features. The instructor felt this step was necessary as few of the students had prior experience with the VED.

Students were required to create video posts each week in which they discussed their understandings and viewpoints on the assigned weekly topics. They were required to respond to at least three classmates' posts. During the discussions, students were expected to relate the topics to their future positions as teachers and describe how they felt the technologies under discussion may or may not aid in student learning. They were also required to respond via text reply to at least three of their classmates' video posts. The instructor responded to student posts in order to model critical discussion and to demonstrate to students that this activity was considered an important part of the course (Kawachi, 2013).

Follow-up responses for each initial video post were text-based. Responses could not be recorded directly on the VED site and it was decided not to further burden students by requiring them to create a video response outside of the platform structure. Given that some students experienced discomfort creating video posts, or felt that video posts compromised their privacy, they were given the option to create initial posts via text. Only two students chose this option for the duration of the course, and both had elected not to participate in the study.

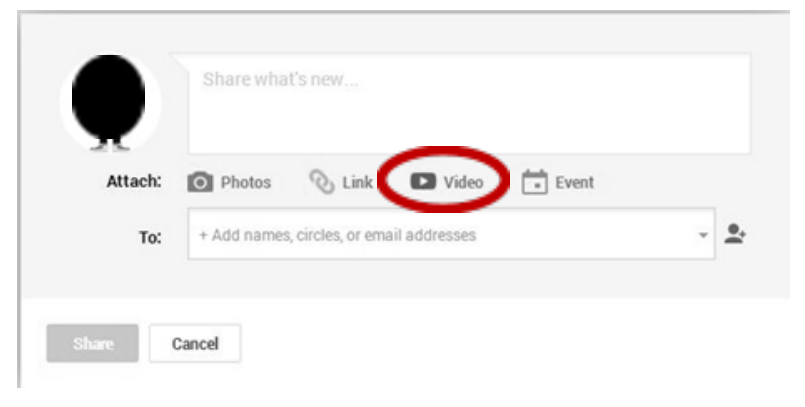

Figure 4. Posting screen for video discussion posts

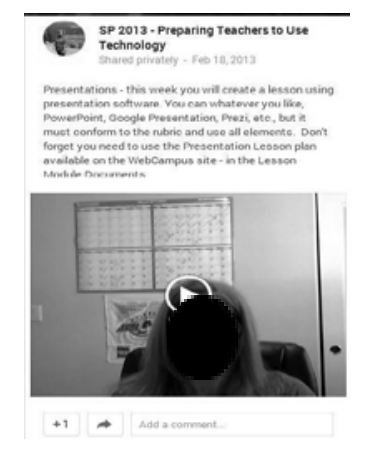

Figure 5. Weekly video post created by course instructor 
Hangouts, the videoconferencing feature of the VED, were scheduled using the Event Calendar (Figure 6). The Event calendar afforded the ability to schedule several types of events and provided email reminders of upcoming events. The instructor used the videoconference feature in conjunction with the screen share option to give a tour of the VED thereby increasing the familiarity of the VED platform for the students. Students were instructed that the Event Calendar could be used to schedule videoconferencebased office hours (Figure 7). Students also had the option to schedule impromptu videoconferences with the instructor if they required extra help, or with fellow students for collaborative or social purposes. On four occasions three different students used the event scheduler to set up office hours, and during the collaborative project students used the event scheduler to set up times to meet with their groups using the videoconferencing feature.

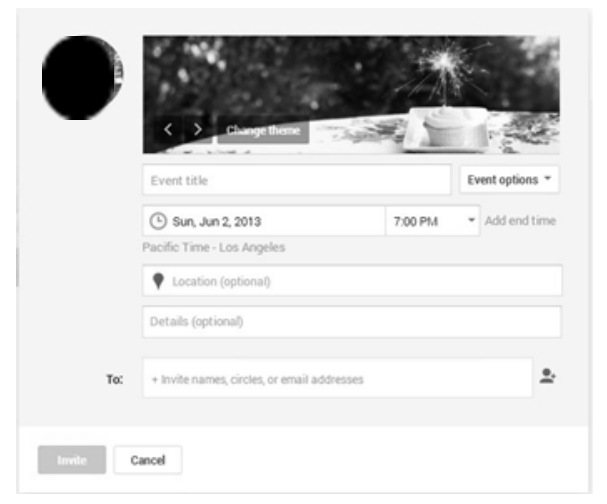

Figure 6. Screen used to create an Event in Google+

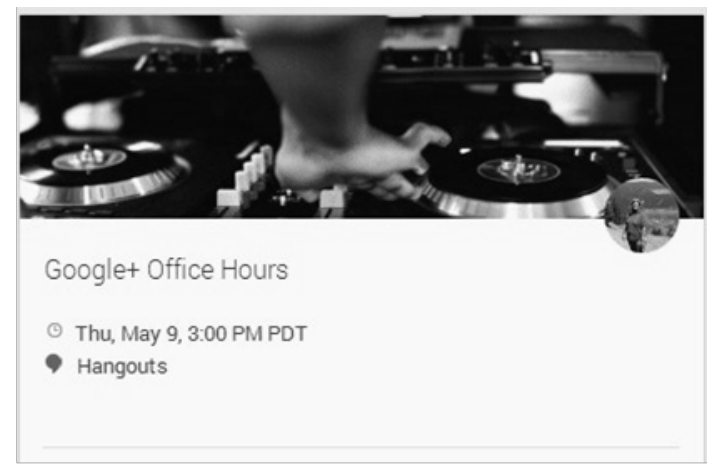

Figure 7. Scheduled office hours using the Google+ Events feature

Administering the Presence Surveys and Student Interviews. The social presence and teaching presence surveys were administered online. The links to the surveys were provided to students via Gmail, the TBD mail system, and posted to the VED course page. The surveys were administered towards the end of week 14 to ensure that both groups of students, the VED group and the TBD group, had equal time using the two different platforms.

Student interviews were conducted towards the end of the term to enable participants to describe their experiences and make judgments as to any differences they felt in social and/or teaching presence. As there was only a short window of time to conduct the interviews before summer break, it was determined that only half of the participants would be interviewed. A stratified sampling method was used. Two students were randomly selected from each of the four subgroups: students that (a) started with TBD and no videoconference with the instructor, (b) started with TBD and videoconference with the instructor, (c) started with VED and no videoconference with the instructor, and (d) started with VED and videoconference with the instructor. The videoconference/no videoconference designations were included as a number of students did not participate in a videoconference with the instructor and it was believed this may have an effect on their feelings of teaching presence. One of the eight students selected did not wish to participate in the interview and another was selected using the same method described above. Due to scheduling and technical difficulties, only six out of the eight interviews were conducted.

Google Hangout On Air was used to conduct the interviews as it allowed Hangout sessions to be digitally recorded and stored in the researcher's YouTube account. YouTube is a web-based videosharing password protected site that allows users to store, upload, edit, and share videos. The interview videos were stored with "private" selected for the sharing level which requires the user's password in 
order to view the video. As several of the interview questions pertained to the instructor, interviews were conducted by the other researchers unknown to the students to allow the students to be more open in their responses. The interviews were transcribed using the YouTube voice-to-text transcription feature and checked for correctness by the one of the research members.

\section{Results}

\section{Comparison of Social and Teaching Presence Surveys}

Given the ordinal, dependent nature of the data the Wilcoxon Signed-rank test was used to compare medians as an indicator of student perceived differences in social and teaching presence between the two discussion platforms. The Wilcoxon Signed-rank test uses the sign function of the difference between the medians and the sum of the ranks in order to determine whether the population medians are significantly different. Participants received both surveys simultaneously and responses were matched using the timestamp provided with the responses. The three constructs contained in the Kreijns et al. (2004) instrument, the Sociability Scale, Social Presence Scale, and Social Space Scale, were analyzed separately, as was the Teaching Presence data. Frequency distributions can be found in Appendix A.

The results of the survey indicated that all areas of social and teaching presence were higher for the VED than for the TBD. The Sociability measure was significantly higher for the VED platform $($ Median $=5)$ than for the TBD platform (Median $=2.5),(Z=-8.93, p<.0005, r=0.71)$. The Social Presence measure was significantly higher for the VED platform (Median $=5$ ) than for the TBD platform (Median = 2.5), $(Z=-5.76, p<.0005, r=0.67$. The Social Space measure was significantly higher for the VED platform (Median $=5$ ) than for the TBD platform (Median $=2),(Z=-8.44, p<.0005, r=0.66)$. Finally, the Teaching Presence measure was significantly higher for the VEDE platform (Median $=5$ ) than for the TBD platform (Median $=5),(. Z=-3.11, p<.002, r=0.23$.

\section{Student Voices}

Analysis of the qualitative data was informed by the CoI construct and the categories contained in the presence surveys (Garrison et al., 2000). NVivo®, a qualitative analysis software package, was used to help code the transcripts derived from the six student interviews. The purpose of the interviews was to obtain detailed interpretation as to the meaning behind the survey responses. Initial codes were developed based on definitions of social and teaching presence, as well as the factor descriptions for sociability and social space contained in the Kreijns et al., (2004) instrument and the Shea et al., (2006) instrument. A member of the research team coded all six interviews, consisting of two female and four male participants, using a pre-established code table which was "modified as the exposure to the data increased" (O'Donoghue \& Punch, 2003, p. 89). After analyzing the data using a constant comparison coding method, the following coding schemes were developed: Sociability, Social Presence, Social Space, and Teaching Presence. Teaching Presence included three subcategories: Connectedness, Facilitation of Discussion, and Directing Cognitive Processes. Descriptions and definitions for these codes can be found in Appendix B. The six student interview transcripts were reviewed for specific examples of each category and subcategory where applicable and analyzed to see whether those statements were in agreement with the empirical results from the survey. Pseudonyms were used in the following interview analysis.

Sociability. Sociability concerns the affordances contained in a computer-supported collaborative learning (CSCL) environment. All six participants referred to the video features of the VED in relation to its importance at creating social space and social presence within the online course. Tom felt that the

video features of the VED “made you feel like you're in class instead of just being online.” This is the 
opposite of the feelings John had towards the TBD. He found the lack of video led to a lack of connectedness due to the fact that "you don't see someone." This was a recurring theme in the interviews, the lack of connectedness when participating in a strictly text-based communication discussion board.

Three of the interview participants related how videoconferences during the semester were effective at helping to create a social climate in the course. Bill spoke of noticing "something in the background of somebody I chatted with" and how it provided context to start a conversation that allowed them to get to know one another on a more personal level. Ann felt she established a friendship with Bill during their videoconferences as they discussed their group project and she began to learn about his personal life, something that had never happened in her face-to-face classes.

Social Presence. Feelings of social presence were mentioned in all six of the participants' interviews. Tom discussed how he preferred using the VED to the TBD "because you can hear somebody's voice and see them talking." Ann relayed a particularly effective example about the difference between text-based communication and video communication. During her interview she described how her opinion changed about a classmate she at first thought to be "really uptight" based on his scholarly-type discussion posts in the TBD. As she viewed his video, and participated in videoconference sessions with Bill, she found him to be "personable and just a funny guy." She pointed out at that "you can get a misconception when you just read." Greg's statement summarizes the overall feelings about the difference between the VED and the TBD: "I preferred it [VED] because you can hear somebody's voice...After you do a few Hangouts...you get a lot better feel for them...You know them a lot better than you do just by reading some text. There's no emotion in text.”

Social Space. All of the participants interviewed expressed that they felt they were part of a community. Three students commented on how they felt "part of a class" similar to the feelings of attending a face-to-face course. Ann stated, "I’ve taken many online classes but...this is the first time I've actually felt that I was in a class," and John noted, "I feel like it gets more into that traditional classroom type feel...this is not a typical online class." The term "connectedness" was mentioned by all but one of the participants, and it was mentioned more than once by four of the participants.

This feeling of social space contributed to a willingness to participate in course assignments, particularly the discussion posts. Bill remarked that he looked forward to the discussion posts each week: "You kind of wanted to do your posts and you kind of wanted to watch the other posts as well. I really enjoyed it." Jane felt that the VED allowed her group to get to know one another well enough to understand individual strengths and weaknesses when it came to assigning responsibilities for the group project. Bill felt being able to discuss responsibilities synchronously using videoconferencing facilitated collaboration by group members on various assignments and prevented confusion as to responsibilities later. He noted, there wasn’t a debate of “oh, I didn’t get that email, why didn’t somebody tell me?”

\section{Teaching Presence}

All participants interviewed felt that the VED provided a better platform to communicate with the instructor. Tom stated that it was "very simple to talk to her." Ann relayed how she enjoyed the weekly “coming up” posts. “It’s nice to have your teacher physically telling you, 'okay, hi everybody,' versus just reading it."

Connectedness. The participants felt the video features helped to create a sense of connection with the instructor. Jane noted she "got a lot better feel for her" as concepts in the class were explained and discussed during instructor video posts. Greg stated he "felt extremely connected to my professor." When comparing this course to other online courses he said that other "professors would send emails and reminders this is due here...it was pretty impersonal." This was echoed by John when making a 
comparison between this course and other online courses he had taken in the past; "before when I just had WebCampus and you just kind of know your teachers, they're just kind of anonymous beings." When asked if other instructors should consider using a VED, Jane advocated its use as a means to "get that more in depth relationship with your students.”

Facilitating and Directing Cognitive Processes. The primary reasons for the creation of social presence and teaching presence is to support cognitive presence and increase persistence in online courses (Doherty, 2006; Garrison, Anderson, \& Archer, 2000; Morris, Finnegan, \& Wu, 2005; Shea, Li, \& Pickett, 2006). Although this study did not set out to measure cognitive presence, examples of facilitating cognitive processes in the course were evident during the interviews. One participant provided an example of how teaching presence was created that could lead to the motivation to learn: "Whereas Professor Clark, she's like, wow, that is some crazy weather we had last week. Like this was real time, this was 'I am committed to your education.' I think it makes you feel like she takes you more seriously, she's invested.” Two other students spoke directly about how they felt the VED enhanced their learning experience. One participant stated, "I feel like I learned more with the Google+ interaction...you were able to see them and react to things." Another said "it was easier to retain information when I'm actually watching something... as opposed to reading it.”

\section{Discussion}

In response to the first two research questions social and teaching presence surveys indicated that video-enabled discussions were more effective at helping create social and teaching presence when compared with text-based discussion platforms. The VED was rated significantly higher than the TBD for all three social scale measures: sociability, social presence, and social space. The VED was also rated significantly higher for teaching presence.

The participant interviews helped provide an understanding of how students experienced the course, their classmates, and their teacher due to the nature of the two separate platforms. Interviewees talked about feelings of "connectedness" with their classmates as the VED provided the ability to "see their faces," indicating they experienced lower feelings of isolation when compared with other online courses. These results were consistent with the findings demonstrated by Dickey (2004) that technology can be used to help reduce feelings of isolation among online students. Feelings of group cohesion and affiliation, important components of social presence (Akyol, 2014; Remesal \& Colomina, 2013), were acknowledged in the interviews as well.

Students also indicated the VED videoconferencing tool made collaboration much easier and more productive as it was possible to "know" your group-mates' strengths and weaknesses. The video features of the VED provided the ability to see both verbal and non-verbal social cues, helping develop feelings of trust and belonging demonstrated by Kreijns et al., (2003) to be crucial for group cohesion. Some of the participants had used the videoconferencing tool to brainstorm ideas and assign duties and responsibilities during the collaborative project. It was believed that addressing these issues synchronously in an environment that provided social cues such as facial expressions would help eliminate any misunderstandings, leading to feelings of trust within the groups.

The VED was shown to influence the creation of teaching presence to a greater extent than the TBD, although survey data indicated that the difference in teaching presence was much less than for social presence. This was probably due to the fact the instructor ensured her interactions were equal between both platforms. As with social presence, interviewees talked about feelings of "connectedness" with the instructor. One participant spoke of how the instructor's video posts helped her understand the instructor by "how she would explain things and talk about them." Ease of communication was a second 
theme during the interviews, particularly given both the synchronous and asynchronous nature of the VED.

The topic of creating video posts was discussed during the interviews. Many of the students spoke about their discomfort level at the beginning, or the difficulty in uploading the posts. Even though they were uncomfortable at first, students were willing to overcome their initial reservations in order to create a more inclusive classroom experience. Once students had created a few videos, most described the process as "easy."

Not all of the responses to the VED platform and discussion subgroupings were positive. Two students, neither of whom participated in the interviews, created text-only posts throughout the majority of the course. One student created two video posts at the beginning of the semester and participated in two videoconferences, but decided the experience was too uncomfortable to continue posting by using the video feature. The second student was uncomfortable with social networking sites and never created a video post and did not participate in videoconferences with either the instructor or fellow students. Of the six discussion groups created, one group had two members who were inactive. The two active members were able to carry on in-depth discussions on the weekly topics, but found it difficult to coordinate effort on the collaborative project as they attempted to include the non-active group members. Another group contained a member who had difficulty understanding both the technology and the course instructions which led to late discussion participation throughout the term. However, based on the data described above and the course postings, both the VED and discussion grouping design led to satisfactory collaborations and course experiences.

Overall, the data indicated that the synchronous and asynchronous video applications provided the visual social cues essential to develop trust, helping participants place value on individual contributions (Ryman, Hardham, Richardson, \& Ross, 2009). The participants did report that the VED provided identification with their discussion group, their classmates, and their teacher. The social presence created within the VED aided group identity formation, providing the social-cohesion necessary for collaborative learning (Akyol, 2014; Brandon \& Hollingshead, 1999; Remesal \& Colomina).

For those conducting online courses, it is important to note that teaching presence was enhanced with synchronous and asynchronous video. Online students begin to feel they are part of a learning community as instructors actively guide discourse (Shea 2006). The VED platform increased the "sense of knowing" the instructor and led to student belief that the instructor was invested in their learning. It is equally important that higher education organizations understand the importance of social and teaching presence in relation to online student learning. Resta and Laferriere (2007) state higher education still employs traditional teaching methods, methods which can "create obstacles for faculty who wish to incorporate pedagogical strategies such as CSCL (computer supported collaborative learning)” (p. 76). The VED platform structure for this study occurred outside of the campus technology infrastructure and required an extra time commitment by the instructor as well as the students. Colleges and universities must recognize that "different learning tasks require different environments, support structures, and technological tools" (Resta \& Laferriere, 2007, p. 76), and work with faculty to provide the tools which will help students learn more effectively.

\section{Implications and Limitations}

The experiences shared by the students, coupled with the survey results, indicate that the video affordances of the VED were more effective than the TBD at creating a classroom environment where students and the instructor connected. This is not surprising as research has previously demonstrated the effectiveness of asynchronous video in promoting social and teaching presence (Borup, West, \& Graham, 2012; Skylar, 2009). However, as noted by Lawson, Comber, Gage, and Cullum-Hanshaw (2010), 
videoconferencing opens up new methods for computer supported collaborative learning and current research is lacking as to pedagogical concerns that should drive this type of learning. This study demonstrated a way to address two pedagogical concerns: student access and use. The VED was available to any student with an internet connection thus allowing easy access to the video affordances which helped develop social and teaching presence. Instructor intervention was not required, unlike other video options such as Blackboard Collaborate or Voice Thread. There were many instances in which students interacted with one another via videoconference without including the instructor, indicating that student autonomy may have led to greater use (Lakhal, Khechine, \& Pascot, 2013). It is important that the degree of access required for full participation be studied further.

There are several areas ripe for further study. Most of the studies involving video affordances have been conducted using asynchronous video applications. As Moallem, Pastore, and Martin (2011) demonstrated, a blend of both asynchronous and synchronous video may result in increased outcomes over either format alone. Sites such as the VED which provide access to both synchronous and asynchronous video affordances could be used to extend this research. Participants mentioned other features of the VED that were not part of the study which they preferred to the TBD. For example, students found outside video and document sharing much easier with the VED than with the TBD. The VED also provided greater flexibility due to its mobile application. Students could receive notifications on their mobile devices and respond whenever and wherever they were. An ecological study of this or another social networking site, as compared to the typical learning management system (LMS), could be conducted in order to identify features that could help improve communication and distance learning outcomes.

Finally, perhaps it is time to look at "student presence" from the viewpoint of the instructor. The instructor for this course noticed a difference in feelings of connection between students she interacted with on the TBD and those she interacted with on the VED. It is suspected that online instructors could be subject to feelings of isolation as well (Reed, Aqui, \& Putney, 2009). A platform similar to the VED, or a combination of technologies, could be used to investigate whether synchronous and asynchronous video increases online instructors' connections to their students, and if these connections lead to increased course effectiveness and learning outcomes.

There are limitations to this study. The coding scheme was applied by the researcher/instructor thus biasing the interpretation of the transcripts. The sample size of 16 students was very small. The participants were enrolled in a teacher technology course and may have been more motivated to learn how to use technology than typical online post-secondary students. The instructor was very familiar with the features of the VED and had preconceived notions as to its ability to contribute to social and teaching presences. Therefore the results cannot be generalized to other student populations.

\section{Conclusion}

This study builds on the literature by providing descriptions of the implementation and effectiveness of one pedagogical strategy to help increase teaching and social presence: asynchronous video discussions posts combined with synchronous videoconferencing. Multiple data sources were used to investigate possible differences in feelings of teaching and social presence based on the video affordances of the discussion platform or based on the lack of such video affordances. The findings suggest that the participants felt greater teaching and social presence when discussions occurred with video posts and synchronous videoconferencing as compared to text based discussions. 
Implications for online course discussion structure and possible teacher isolation effects were discussed. Online learning is fast becoming an integral part of education. It is important to identify pedagogically driven tools that can help students and instructors experience success in this environment.

\section{References}

Akyol, Z. (2014). The development of a community of inquiry over time in an online course: Understanding the progression and integration of social, cognitive, and teaching presence. Journal of Asynchronous Learning Networks, 12(3-4), 3-22.

Anderson, T. (2004). Theory and practice of online learning. Edmonton: AU Press, Athabasca University.

Arbaugh, J.; Cleveland-Innes, M.; Diaz, S.; Garrison, R.; Ice, P.; Richardson, J.; \& Swan, K. (2008). Developing a community of inquiry instrument: Testing a measurement of the community of inquiry framework using a mult-institutional sample. Internet and Higher Education, 11(3-4), 133-136. doi: 10.1016/j.iheduc.2008.06.003

Aviv, R., Erlich, Z., Ravid, G., \& Geva, A. (2003). Network analysis of knowledge construction in asynchronous learning networks. Journal of Asynchronous Learning Networks, 7(3), 1-23. doi: 10.1016/j.iheduc.2011.11.001

Borup, J., West, R., \& Graham, C. (2012). Improving online social presence through asynchronous video. Internet and Higher Education, 15(3), 195-203. doi: 10.1016/j.iheduc.2011.11.001

Brandon, D., \& Hollingshead, A. (1999). Collaborative learning and computer-supported groups. Communication Education, 48(2), 109-126. doi: 10.1080/03634529909379159

Buchanan, T., Paine, C., Joinson, A., \& Reips, U-D. (2006). Development of measures of online privacy concern and protection for use on the internet. Journal of the American Society for Information Science and Technology, 58(2), 157-165. doi: 10.1002/asi.20459

Burnsed, B. (2011). Online education may transform higher Ed. Retrieved June 1, 2013, from: http://www.usnews.com/education/onlineeducation/articles/2011/04/20/online-education-maytransform-higher-ed

Cohen, L., Manion, L., \& Morrison, K. (2011). Research methods in education. Oxford: Routledge

Dickey, M. (2004). The impact of web-logs (blogs) in student perceptions of isolation and alienation in a web-based distance learning environment. Open Learning: The Journal of Open, Distance and eLearning, 19(3), 279-291. doi: 10.1080.0268051042000280138

Doherty, W. (2006). An analysis of multiple factors affecting retention in web-based community college courses. Internet and Higher Education, 9(4), 245-255. doi: 10.1016/j.iheduc.2006.08.004

Dooner, A. M., Mandzuk, D., \& Clifton, R. (2008). Stages of collaboration and the realities of professional learning communities. Teaching and Teacher Education, 24(3), 564-574. doi: 10.1016/j.tate.2007.09.009 
Fain, P. (2013, January 16). As california goes? Retrieved June 1, 2013, from Inside Higher Ed: http://www.insidehighered.com/news/2013/01/16/california-looks-moocs-online-push

Gall, M., Gall, J., \& Borg, W. (2003). Educational research: An introduction (7th edition). Boston, MA: A \& B Publications.

Gall, M., \& Gillett, M. (1980). The discussion method in classroom teaching. Theory Into Practice, 19(2), 98-103. doi: 10.1080/00405848009542881

Garrison, R., Anderson, T., \& Archer, W. (2000). Critical inquiry in a text-based environment: Computer conferencing in higher education. The Internet and Higher Education, $2(2$ - 3), 87-105. doi: 10.1016/S1096-7516(00)00016-6

Garrison, D., Anderson, T., \& Archer, W. (2001). Critical thinking, cognitive presence, and computer conferencing in distance education. American Journal of Distance Education, 15(1), 7-23. doi: $10.1080 / 08923640109527071$

Greenlaw, S., \& DeLoach, S. (2003). Teaching critical thinking with electronic discussion. Journal of Economic Education, 34(1), 36-53. doi: 10.1080/00220480309595199

Gunawardena, C., \& Zittle, F. (1997). Social presence as a predictor of satisfaction within a computermediated conferencing environment. American Journal of Distance Education, 11(3), 8-26. doi: 10.1080-08923649709526970

Joo, Y. J., Kim, K. Y., \& Kim, E. K. (2011). Online university students' satisfaction and persistence: Examining perceived level of presences, usefulness, and ease of use as predictors in a structural model. Computers \& Education, 57(2)1654-1664. doi: 10.1016/j.compedu.2011.02.008

Kaste, M. (2011). Facebook's newest challenger: Google Plus. Retrieved June 1, 2013, from NPR: http://www.npr.org/2011/06/29/137507567/facebooks-newest-challengergoogle-plus

Kawachi, P. (2013). Online social presence and its correlation with learning. International Journal of Social Media and Interactive Learning Environments, 1(1). 19-31. doi: 10.1504/IJSMILE.2013.051653

Kay, R. (2006). Developing a comprehensive metric for assessing discussion board effectiveness. British Journal of Educational Technology, 37(5), 761-783. doi: 10.111/j.1467-8535.2006.00560.x

Kreijns, K., Kirschner, P., \& Jochems, W. (2002). The sociability of computer-supported collaborative learning environments. Educational Technology \& Society, 5(1), 1436-4522.

Kreijns, K., Kirschner, P., \& Jochems, W. (2003). Identifying pitfalls for social interaction in computersupported collaborative learning environments: A review of the research. Computers in Human Behavior, 19(3), 335-353. doi: 10.1016/S0747-5632(02)00057-2

Kreijns, K., Kirschner, P., Jochems, W., \& Burren, H. (2004). Determining sociability, social space, and social presence in (a)synchronous collaborative groups. CyberPsychology \& Behavior, 7(2), 155172. doi: $10.1089 / 109493104323024429$ 
Lakhal, S., Khechine, H., \& Pascot, D. (2013). Student behavioral intentions to use desktop video conferencing in a distance course: integration of autonomy in the UTAUT model. Journal of Computing in Higher Education, 1-29. doi:10.10071s12528-013-9069-3

Lawson, T., Comber, C., Gage, J., \& Cullum-Hanshaw, A. (2010). Images of the future for education? Videoconferencing: A literature review. Technology, Pedagogy and Education, 19(3), 295-314. doi: 10.1080/1475939X.2010.513761

Lee, K. (2004). Presence, explicated. Communication Theory, 14(1), 27-50. doi: 10.1111/j.14682885.2004.tb00302.x

Liu, S., Gomez, J., \& Yen, C. J. (2009). Community college online course retention and final grade: Predictability of social presence. Journal of Interactive Online Learning, 8(2), 165-182.

Lowry, P. B., Roberts, T. L., Romano, N. C., Cheney, P. D., \& Hightower, R. T. (2006). The impact of group size and social presence on small-group communication: Does computer-mediated communication make a difference?. Small Group Research, 37(6), 631-661. doi: $\underline{10.1177 / 1046496406294322}$

Moallem, M., Pastore, R., \& Martin, M. (2011). A comparative study on the impact of communication tools on student learning, motivation, self-regulation, and satisfaction. In Society for Information Technology \& Teacher Education International Conference (Vol. 2013, No. 1, pp. 2286-2306). Retrieved from http://www.editlib.org/p/48448/

Morris, L., Finnegan, D., \& Wu, S-S. (2005). Tracking student behavior, persistence, and achievement in online courses. Internet and Higher Education, 8(3), 221-231. doi: 10.1016/j.iheduc.2005.06.009

Munro, B. (1981). Dropouts from higher education: Path analysis of a national sample. American Educational Research Journal, 18(2), 133-141. doi: 10.3102/00028312018002133

Nagel, L., \& Kotze, T. (2010). Supersizing e-learning: What a CoI survey reveals about teaching presence in a large online class. Internet and Higher Education, 13(1), 45-51. doi: 10.1016/j.iheduc.2009.12.001

Nowak, K. (2001). Defining and differentiating copresence, social presence, and presence as transportation. In Presence 2001 Conference, Philadelphia, PA, (pp. 1-23). Retrieved from http://d111ifh5i719sd.cloudfront.net/wp-content/blogs.dir/36/files/2009/10/Nowak1.pdf

O'Donoghue, T., \& Punch, K. (2003). Qualitative educational research in action. New York, NY: RoutledgeFarmer.

Patterson, B., \& McFadden, C. (2009). Attrition in online and campus degree programs. Online Journal of Distance Learning Administration, 12(2), 1-11.

Pinsk, R., Curran, M., Poirier, R., \& Coulson, G. (2014). Student perceptions of the use of studentgenerated video in online discussions as a mechanism to establish social presence for nontraditional students: A case study. Issues in Information Systems, 15(1), 267-276.

Reed, K., Aqui, Y., \& Putney, L. (2009). Evaluation of an evolving virtual high school. Educational Media International, 46(4), 281-294. doi: 10.1080/09523980903387522 
Remesal, A., \& Colomina, R. (2013). Social presence and online collaborative small group work: A $\begin{array}{lllllll}\text { socioconstructivist account. Computers \& Education, 60(1), 357-367. } & \text { doi: }\end{array}$ $\underline{10.1016 / \text { j.compedu.2012.07.009 }}$

Resta, P., \& Laferriere, T. (2007). Technology in support of collaborative learning. Educational Psychology Review, 19(1), 65-83. doi: 10.1007/s10648-007-9042-7

Roblyer, M., \& Wiencke, W. (2003). Design and use of a rubric to assess and encourage interactive qualities in distance courses. American Journal of Distance Education, 17(2), 77-98. doi: 10.1207/S15389286AJDE1702_2

Rosenblum, D. (2007). What anyone can know: The privacy risks of social networking sites. IEEE Security and Privacy, 5(3), 40-49. doi: 10.1109/MSP.2007.75

Rovai, A. (2001). Building classroom community at a distance: A case study. Educational Technology Research \& Development, 49(4), 33-48. doi: 10.1007/BF02504946

Rovai, A. (2003). In search of higher persistence rates in distance education online programs. Internet and Higher Education, 6(1), 1-16. doi: 10.1016/S1096-7516(02)00158-6

Rovai, A. (2003). In search of higher persistence rates in distance education online programs. Internet and Higher Education, 6(1), 1-16. doi: 10.1016/S1096-7516(02)00158-6

Rovai, R., \& Wighting, M. (2005). Feelings of alienation and community among higher education students in a virtual classroom. Internet and Higher Education, 8(2), 97-110. doi: 10.1016/j.iheduc.2005.03.001

Ryman, S., Hardham, G., Richardson, B., \& Ross, J. (2009). Creating and sustaining online learning communities: Designing for transformative learning, International Journal of Pedagogies and Learning, 5(3), 32-45. doi: 10.5172/ijpl.5.3.46

Schellens, T., \& Valcke, M. (2004). Fostering knowledge construction in university students through asynchronous discussion groups. Computers \& Education, 46(4), 349-370. doi: 10.1016/j.compedu.2004.07.010

Shea, P. (2006). A study of a students' sense of learning community in online environments. Journal of Asynchronous Learning Networks, 10(1), 35-44. doi: 10.1016/j.iheduc.2006.06.005

Shea, P., Li, C., \& Pickett, A. (2006). A study of teaching presence and student sense of learning community in fully online and web-enhanced college courses. Internet and Higher Education, 9(3), 175-190. doi: 10.1016/j.iheduc.2006.06.005

Skylar, A. (2009). A comparison of asynchronous online text-based lectures and synchronous interactive web conferencing lectures. Issues in Teacher Education, 18(2), 69-84.

Tinto, V. (1997). Classrooms as communities: Exploring the educational character of student persistence. The Journal of Higher Education, 68(6), 599-623. 
Tu, S. H., \& McIsaac, M. (2002). The Relationship of Social Presence and Interaction in Online Classes. American Journal of Distance Education, 16(3), 131-150. doi: 10.1207/S15389286AJDE1603_2

Wang, Q., \& Woo, H. (2007). Comparing asynchronous online discussions and face-to-face discussions in a classroom setting. British Journal of Educational Technology, 38(2), 272-286. doi: 10.1111/j.1467-8535.2006.00621.x

Zydney, J., deNoyelles, A., \& Seo, K. (2012). Creating a community of inquiry in online envrionments: An exploratory study on the effect of a protocol on interactions within asynchronous discussions. Computers \& Education, 58(1), 77-87. doi: 10.1016/j.compedu.2011.07.009

\section{Appendix A Survey Response Frequency Graphs}

Figure 5: Frequency Comparison of Survey Responses for the Sociability Measure

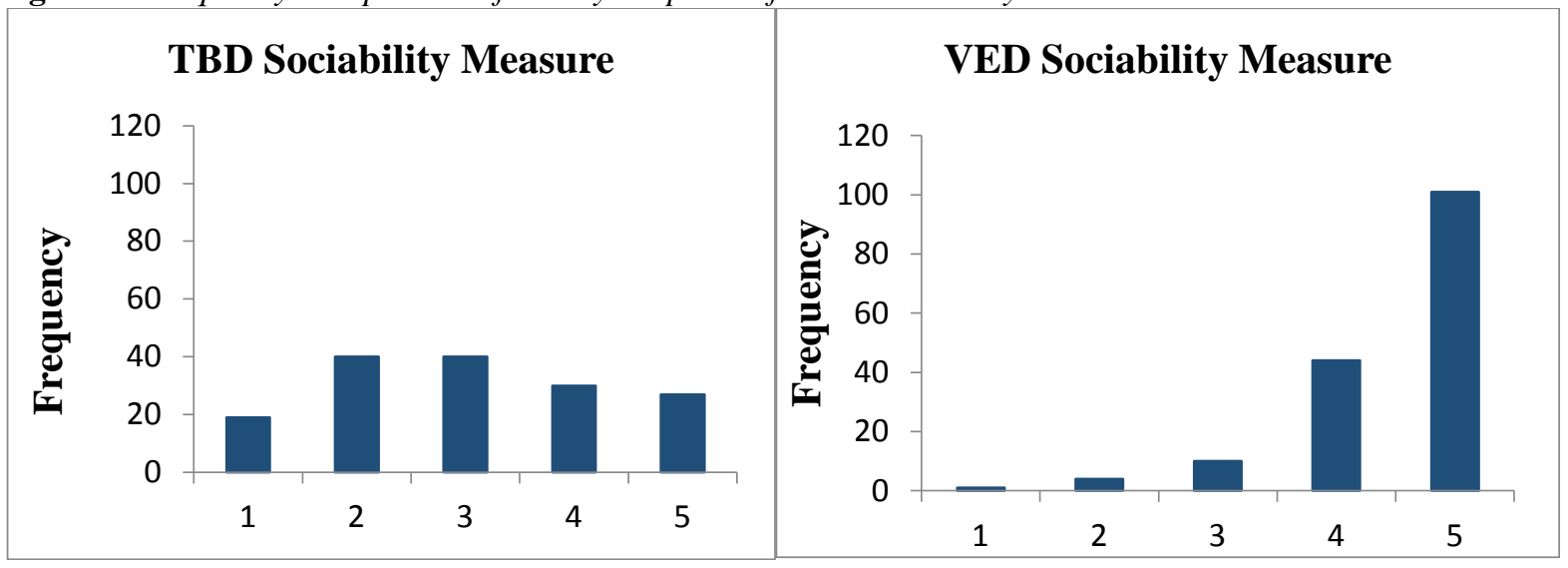

$\mathrm{n}=160$ Survey responses were scored on a scale from 1 to 5 , with 1 being 'strongly disagree' to 5 'strongly agree'

Figure 6: Frequency Comparison of Survey Responses for the Social Presence Measure

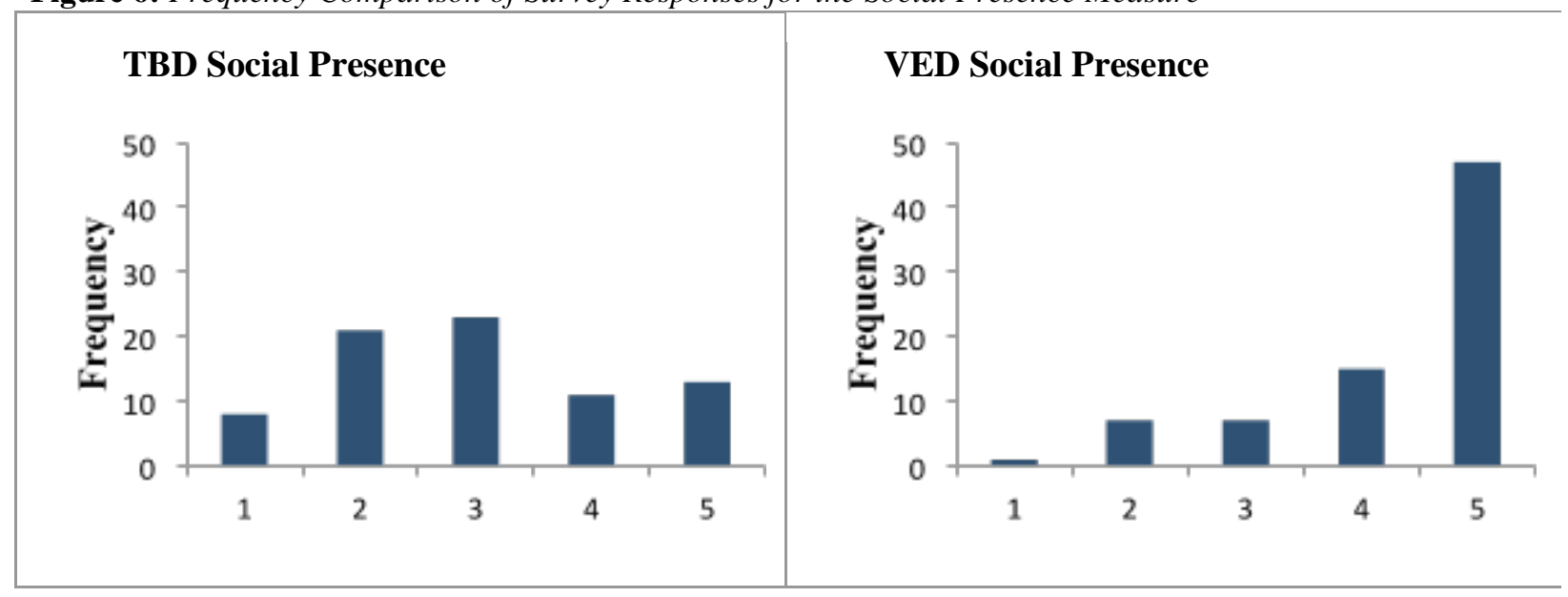

$\mathrm{n}=80$ Survey responses were scored on a scale from 1 to 5 , with 1 being 'strongly disagree' to 5 'strongly agree' 
Figure 7: Frequency Comparison of Survey Responses for the Social Space Measure

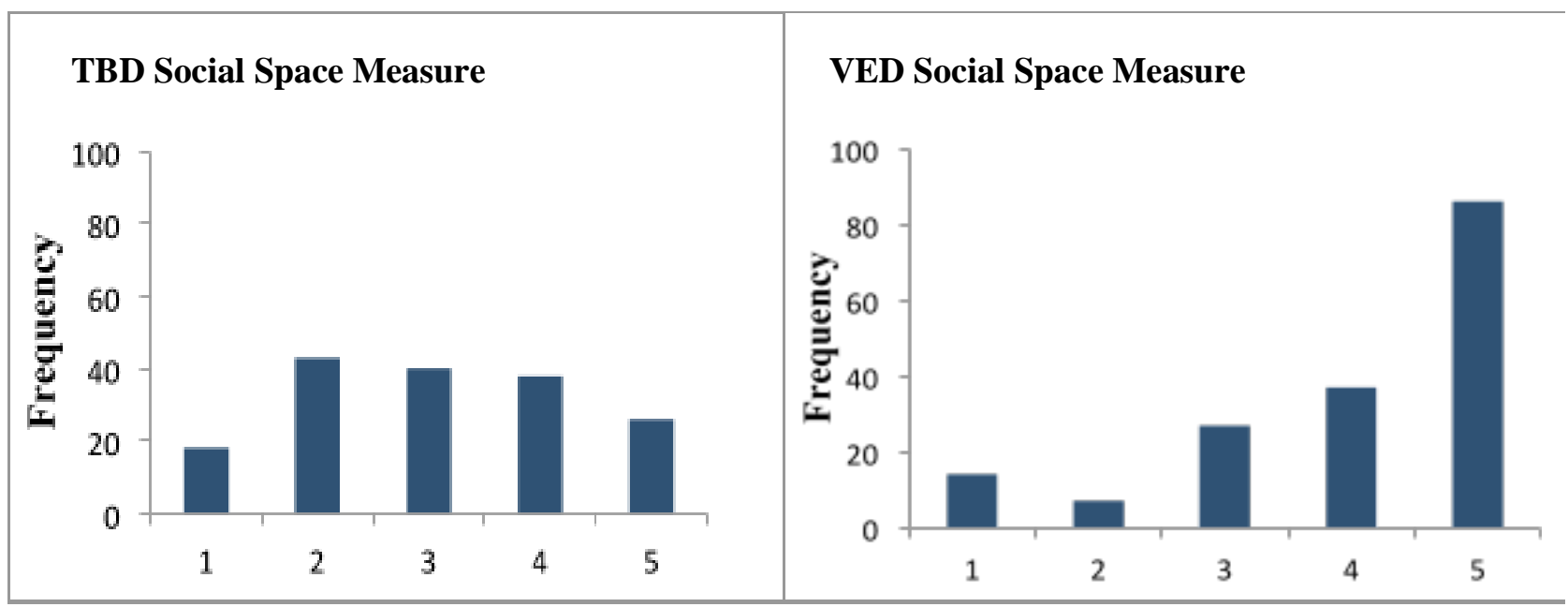

$\mathrm{n}=176$ Survey responses were scored on a scale from 1 to 5 , with 1 being 'strongly disagree' to 5 'strongly agree'

Figure 8: Frequency Comparison of Survey Responses for the Teaching Presence Measure

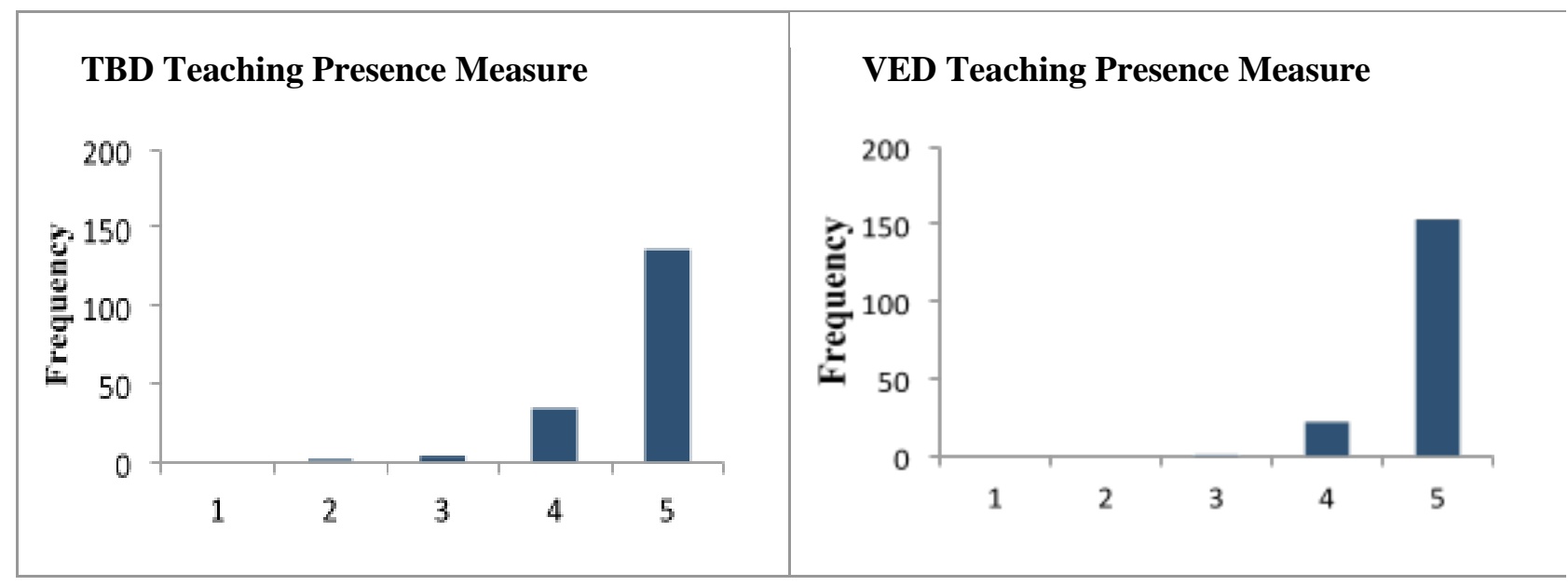

$\mathrm{n}=176$ Survey responses were scored on a scale from 1 to 5 , with 1 being 'strongly disagree' to 5 'strongly agree' 


\section{Appendix B Social and Teaching Presence Coding Categories and Definitions}

\begin{tabular}{|c|c|}
\hline Fategory & Definition \\
\hline Social Space & $\begin{array}{l}\text { A social space is "characterized by effective work relationships, strong group cohesiveness, } \\
\text { trust, respect and belonging, satisfaction, strong sense of community" (Kreijns et al., 2004, p. } \\
\text { 157). }\end{array}$ \\
\hline Social Presence & $\begin{array}{l}\text { Social presence refers to "the degree of illusion that the other in the communication appears } \\
\text { to be a 'real physical person"” (Kreijns et al., 2004, p. 157). }\end{array}$ \\
\hline Sociability & $\begin{array}{l}\text { "...the extent to which a social space" arises based upon "the quality of the set of social } \\
\text { affordances" contained in the CSCL environment. (Kreijns et al., 2002, p. 13). }\end{array}$ \\
\hline $\begin{array}{l}\text { Teaching } \\
\text { Presence } \\
\text { Connectedness } \\
\text { Facilitating } \\
\text { discussion } \\
\text { Directing } \\
\text { cognitive } \\
\text { processes }\end{array}$ & $\begin{array}{l}\text { “...effective design, facilitation, and direction of cognitive and social processes on the part of } \\
\text { the online instructors" (Shea et al., 2006, p. 177). } \\
\text { Expressions of connectedness to the instructor. } \\
\text { Expressions that instructor helped guide and direct discussions. } \\
\text { Expressions that instructor is interested in learning outcomes of students. }\end{array}$ \\
\hline
\end{tabular}

